\title{
PROJECTION OF THE ROMA POPULATION IN BULGARIA (2020-2050)
}

DOI: http://dx.doi.org/10.18509/GBP.2019.35

UDC: $314.114-053(497.2:=214.58) " 2020 / 2050 "$

\author{
Nadezhda Ilieva \\ Boris Kazakov \\ National Institute of Geophysics, Geodesy and Geography, \\ Bulgarian Academy of Sciences, Bulgaria
}

\begin{abstract}
The paper presents the results of a demographic projection of the population and the age structure of the Roma ethnic group in Bulgaria, as well as the main factors for the specific demographic and socio-economic development of the Roma. The authors discuss the reasons for that discrepancy and attempt to estimate the number of Roma people in Bulgaria as of 2015 and make a projection of the population number of the country as a whole (2020-2050) and of the Roma share and number in particular, including its basic age structure - the $0-14 ; 15-64$ and the $65+$ age groups - by using the method of cohort components. Migration mobility and demographic transition phases have also been considered and some key conclusions have been made regarding the future trends concerning the number and share of the Roma ethnic group in Bulgaria.
\end{abstract}

Keywords: Roma ethnic group, demographic projection, cohort components method, age structure

\section{INTRODUCTION}

The Roma are a specific ethnic community with no analogue in Europe. It is divided into many different, and sometimes contradicting groups, subgroups and meta units, each with their own ethnic and cultural characteristics. Historical, political and economic factors have created great differences among the Roma across Europe but also within Bulgaria itself. It wouldn't be incorrect to say that the unifying element of the Roma ethnic group is the attitude of the macrosociety towards it, thus creating a separate social category with common problems. Those problems are related to poverty, marginalization, exclusion from the labor market, segregation within the educational system, poor access to social services, extreme forms of spatial segregation, exclusion from the practice of active citizenship, intolerance, discrimination, prejudice, negative stereotypes, etc. The term "European or trans-national minority" corresponds largely to the essence of the Roma ethnic group.

The main objective and the expected results of the study are to estimate the number, the relative share of the Roma population, as well as its age structure, for the $2020-2050$ period.

\section{SCIENTIFIC APPROACH AND THE METHODOLOGY OF THE RESEARCH}

In the elaboration of the demographic projection, the method of cohort components has been used. There are conceptual advantages to this method since it groups the population by age cohorts (five-year age groups) and calculates the characteristics (coefficients) of 
each group separately. Age decomposition makes the evaluation of the future demographic potential by age groups possible. These advantages make this method the best compared to other population projection methods (such as the method of extrapolation, the symptomatic analysis, the regression analysis, etc.). It has been rated as one of the most accurate population projection methods and is most often used to make population estimates for a 50-year-period of time, making it suitable for preparing demographic projections for a specified time frame. The technology of population projection with the method of cohort components for each period in examination, passes through the following stages:

- Calculation of the values of key demographic indicators (number of population divided into five-year interval age groups; the surviving probability coefficient (Px); the death probability coefficient $(\mathrm{Qx})$; the number of women in fertile age; the general fertility rate);

- Projection of the population number for all age groups except for the first one;

- Calculation of the number of births in the first age group (0-4 years) based on the fertility rate and the number of women in fertile age;

- Correction of the number of births in the age group of 0-4 years, according to the survival probability coefficient (Px);

- Final total population projection by age groups - of the total population of Bulgaria, as well as that of the Bulgarian and the Roma ethnic communities, based on the results from points 2,3 and 4 .

Since the hypothesis of lack of migration is unlikely, the next step in elaborating the projection is setting different levels of migration mobility in the three scenarios of the population projection (realistic, optimistic and pessimistic).

In the different scenarios of the projection, different quantitative outcomes of the expected future development of the natural and migration growth were set, both for the total population and for the different ethnic communities in the country. Those scenarios are hypothetical in their essence and are based on the current dynamics of the birth and death rates, the number of women in fertile age, the fertility coefficient and the immigration and emigration occurrence. The death probability $(\mathrm{Qx})$, and the survival probability $(\mathrm{Px})$ values were taken from the life tables elaborated by the National Statistical Institute of Bulgaria.

In making the demographic projection, the demographic transition phases which the Bulgarian and the Roma communities are in, were also taken into account. In determining the projected population number and basic demographic structures, the influence of two main groups of factors has been taken into consideration: ones stimulating the demographic development and ones retaining the demographic development (such as deepening of the economic crisis in the country, reduced investment activity, transformation of the "two-child family model" into a "one-child model", etc.).

In accordance with the purpose of the study, a projection of the population of: 1) Bulgaria, 2 ) of the Roma ethnic community and 3) of the Bulgarian ethnic community for the 2020 2050 period, an estimate (for the period between 2020 and 2050 at 5-year intervals) of each above-mentioned group of population is suggested (number, relative share and age structure). By applying the projected values of the discussed demographic indicators and considering the influence of the above mentioned two groups of factors, the demographic projection of the total population of Bulgaria was elaborated in three scenarios: 
- $1^{\text {st }}$ scenario (realistic, current-trend-based) - based on the assumption of preservation of the current demographic, socio-economic and ethno-cultural development trends concerning the Roma and the Bulgarian population groups;

- $2^{\text {nd }}$ scenario (optimistic) - based on the assumption that the demographic development will occur under favorable socio-economic conditions in the country;

- $3^{\text {rd }}$ scenario (pessimistic) - the development of the population is estimated under the hypothesis of declining socio-economic development of the country and worsening of the demographic processes.

All scenarios of the population projection are elaborated in two variants: 1) considering the official statistical data, according to which the number of Roma was 325000 people as of 2011 (the year of the last population census in Bulgaria) and 2) considering the expert assessment, according to which the number of Roma in as of 2015 was approximately 720000 people [2].

\section{OUTPUT DATA ON THE NUMBER OF ROMA.}

A major problem in assessing the situation of the Roma ethnic group not only in Bulgaria but also in other European countries, is the lack of accurate data. There are major discrepancies between the number of Roma recorded by official censuses and their number according to scientific-empirical research in this field of study. One of the reasons for that is the specificity of the Roma ethnic group, which is not homogeneous as such. Another reason for the "distortion" of the information on the ethnicity during the conduction of population censuses, is the widespread phenomenon of "preferred ethnic identity" (the public declaration of another non-Roma ethnicity). Popov [7] points out several reasons that incite the Muslim Roma in Bulgaria to identify themselves as Turks, such as the negative attitude of all ethnic groups towards the Roma, the higher prestige of the Turkish ethnic community, the common religious, cultural and linguistic traditions, etc. Tomova [8] indicates that some $2 / 3$ of the respondents confidently declare their belonging to the Roma community, while among the remaining $1 / 3$ there is a preference for other ethnic identity such as the Turkish. According to Tomova [8], $47.3 \%$ of all Roma people in the country consider themselves part of the Bulgarian Roma group, $46.2 \%$ of the respondents declare themselves as Turkish Roma and $5.1 \%$ of the declare themselves as Vlach Roma.

In the first variant of the projection, according to which the number of Roma was 325343 , served as output data. The second variant, however, adopted as output data the "actual" number of the Roma as of 2015, calculated on the basis of the trends in the demographic processes among the Roma population in recent decades. A revision of the literature on the topic has shown that the experts' estimate of the number of Roma varies within large limits. Among the assessments giving the highest percentage of Roma is that of the Council of Europe, according to which the Roma make up $10.33 \%$ of the population in Bulgaria. According to Marushiakova \& Popov [4] in the early 1990s the number of Roma was fixed at 800000 , but unfortunately this assessment was made without mentioning any specific methodology. In 1994, Liegeois determined the number of Roma in Bulgaria to be somewhere between 700000 and 800000 people [3]. He too did not mention how he had come up with such a number, but he had been most likely influenced by publications of Bulgarian authors working on the topic. Considerably more moderate and closer to the data of the Ministry of Interior from 1989 is the evaluation of Tomova from 577000 to 600000 people [8]. Pamporov [5] estimated the number of Roma in 2007 to be somewhere between 638162 and 815313 people. According to our estimates, as 
the number of Roma people had reached some 720000 people as of 2015 - the year which is considered a base year when carrying out the current projection of the Roma population in its second variant (the one based on the expert assessment of the number of Roma).

\section{BASIC DEMOGRAPHIC INDICATORS OF THE ROMA IN BULGARIA.}

The Roma are the only ethnic group in the country that has been increasing its population number, in spite of what the data of the official statistics show. The leading factor for the growing number of the Roma is their natural growth rate. Based on official data gathered during population censuses, the natural growth rate of the Roma population for the 19922001 period was around $18.7 \%$. Assuming that the death rate was around $8.0 \%$, the birth rate for that period can be evaluated at about $26.0 \%$. These data are confirmed by the study of Tomova [9]. Studies of the latter author [11] show that, based on "the estimates of experts - doctors, representatives of local authorities, social services and the police, who work with Roma people on a regular basis, state that the fertility in this community has decreased significantly in recent years". One of the reasons stated is the increased labor migration of Roma people from 2002 onwards to other EU Member States and the increasing educational level of young women. Following 2002, systematic efforts to keep $100 \%$ of the Roma children in primary school (grades 1-4) and also efforts to keep them in school as long as possible, have been made [9]. All these measures have led to lower birth rates. However, the considerably younger age structure of that community exhibits a high share of Roma women in young age groups: as of 2011, nearly $39.1 \%$ of the Roma in Bulgaria were under 20 years old, as opposed to $22.4 \%$ of the Bulgarian Turks and $15.5 \%$ of the Bulgarians. The better age structure of the Roma will continue to predetermine the higher birth rates in the medium and in the long term, despite the continuing reduction of the number of children in their households.

According to the developed scenarios, the following quantitative indicators of the prognosis have been defined:

- First scenario (under the hypothesis of convergence) - "realistic scenario" (RS) based on the assumption that the demographic behavior of the Roma will remain unchanged.

- Second scenario (relative acceleration) - "optimistic scenario" (OS) - the most unlikely, since it involves an expected increase of the birth rate and the general fertility rate in both the Roma and the Bulgarian population - something very unlikely to happen.

- Third scenario (relative deceleration) - "pessimistic scenario" (PS) - where the development of the population in this case is forecasted under the hypothesis of adverse socio-economic processes in the country. In this scenario, a decrease of the values of the birth rate and the general fertility rate among Roma is expected, as well as an additional deterioration of the demographic indicators among the Bulgarian population. As for the Roma ethnic group, a reduction of unwanted pregnancies and births is provisioned, as well as a decline in early marriages and fertility, shrinking of the active fertile period of women, changes in the ideals of Roma concerning the larger number of children in the family, strengthening of the processes of planning the number of children in the family, strengthening of the integration processes, breaking of the civil marriage model and transition to marital cohabitation without marriage, an increase of the marriage age, an overcoming the isolation and the subordinate role of women in traditional households, changes in cultural stereotypes, permanent displacement of births to higher ages, etc. 
The number of the Roma population is expected to increase at a rate of between 2400 and 7500 people per year, depending on the scenarios adopted, if the results of the official statistics (OD) are considered, and between 5000 and 15400 people per year in the case where the expert assessment (EA) is taken as a data baseline.

According to the different scenarios of the projection, the number of Roma in Bulgaria will continue to increase. In case the number of the Roma population is taken from the official statistics, the estimates show that this number will reach values of between 363 000 and 393000 by 2020 and will increase up to 438000,556000 and 619000 by 2050, according to the pessimistic, the realistic and the optimistic scenario respectively (Table 1, Fig. 1).

Table 1. Estimated number of the Roma ethnic group and the total population of Bulgaria (2020-2050)

\begin{tabular}{|c|c|c|c|c|c|c|}
\hline \multicolumn{7}{|c|}{ According to the official statistical data } \\
\hline \multirow[b]{2}{*}{ Year } & \multicolumn{2}{|r|}{ RS } & \multicolumn{2}{|c|}{ OS } & \multicolumn{2}{|c|}{ PS } \\
\hline & Roma & $\begin{array}{c}\text { Total } \\
\text { population }\end{array}$ & Roma & $\begin{array}{c}\text { Total } \\
\text { population }\end{array}$ & Roma & $\begin{array}{c}\text { Total } \\
\text { population }\end{array}$ \\
\hline 2020 & 383582 & 6707001 & $\mathbf{3 9 3 2 4 5}$ & 6942415 & 363290 & 6628530 \\
\hline 2025 & 412707 & 6376373 & 427610 & 6717077 & 381410 & 6262806 \\
\hline 2030 & 441231 & 6031709 & 462669 & 6486226 & 396974 & 5882228 \\
\hline 2035 & 469507 & 5696946 & 498837 & 6273365 & 410238 & 5510731 \\
\hline 2040 & 497702 & 5370966 & 536349 & 6075663 & 421274 & 5147627 \\
\hline 2045 & 526766 & 5059096 & 576515 & 5902704 & 430595 & 4797132 \\
\hline 2050 & 556939 & $\mathbf{4 7 5 4 2 8 7}$ & 619897 & $\mathbf{5 7 4 9 7 8 0}$ & 438094 & 4451705 \\
\hline \multicolumn{7}{|c|}{ According to the expert assessment } \\
\hline Year & Roma & $\begin{array}{c}\text { Total } \\
\text { population }\end{array}$ & Roma & $\begin{array}{c}\text { Total } \\
\text { population }\end{array}$ & Roma & $\begin{array}{c}\text { Total } \\
\text { population }\end{array}$ \\
\hline 2020 & 784041 & 6707001 & 803791 & 6942415 & 742564 & 6628530 \\
\hline 2025 & 843572 & 6376373 & 874034 & 6717077 & 779601 & 6262806 \\
\hline 2030 & 901875 & 6031709 & 945693 & 6486226 & 811414 & 5882228 \\
\hline 2035 & 959671 & 5696946 & 1019622 & 6273365 & 838525 & 5510731 \\
\hline 2040 & 1017300 & 5370966 & 1096296 & 6075663 & 861082 & 5147627 \\
\hline 2045 & 1076708 & 5059096 & 1178395 & 5902704 & 880135 & 4797132 \\
\hline 2050 & 1138382 & 4754287 & 1267067 & 5749780 & 895463 & 4451705 \\
\hline
\end{tabular}

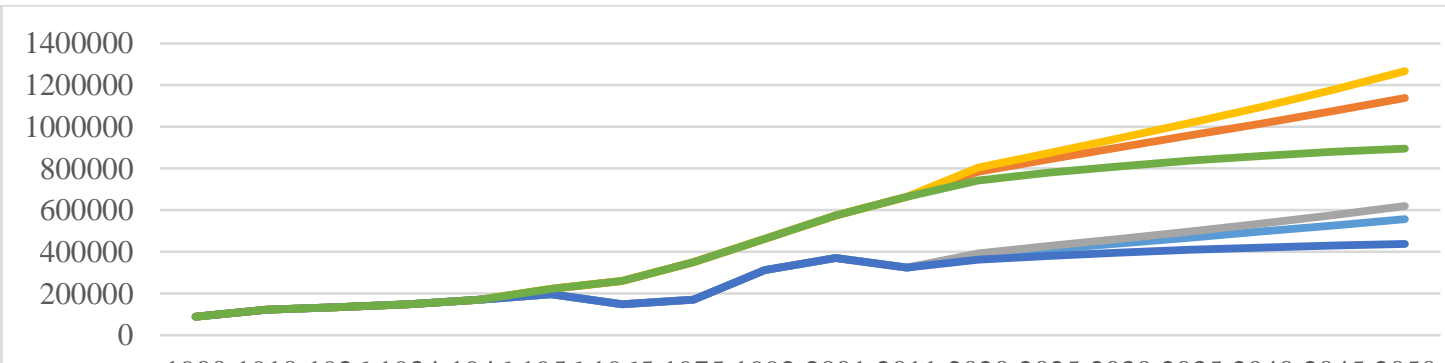

190019101926193419461956196519751992200120112020202520302035204020452050

$\longrightarrow \mathrm{RS}(\mathrm{OD})=\mathrm{RS}(\mathrm{EA}) \longrightarrow \mathrm{OS}(\mathrm{OD})=\mathrm{OS}(\mathrm{EA}) \longrightarrow \mathrm{PS}(\mathrm{OD}) \longrightarrow \mathrm{PS}(\mathrm{EA})$

Figure 1. Estimated number of the Roma ethnic group in Bulgaria (2020-2050).

Depending on the considered levels of fertility and mortality, in 2020 the number of Roma is expected to be somewhere between 742000 and 803000 . By 2050 the number of the Roma population will have increased according to all scenarios, and it is expected to reach 895000,1138000 or 1267000 according to the three scenarios respectively (Fig. 1), or 
an increase by $5.0 \%-12.0 \%$ by 2020 , and between $20.3 \%-54.6 \%$ in the next thirty years (2020-2050) (Fig.2).

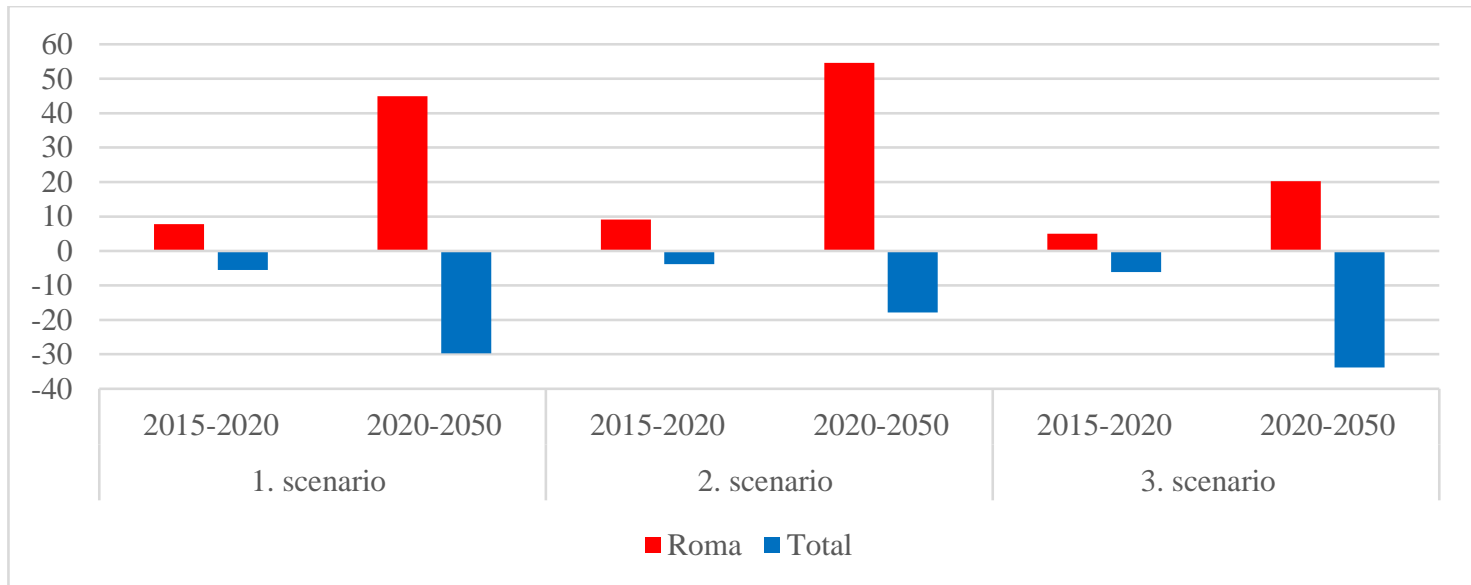

Figure 2. Expected relative changes (\%) in the number of the Roma ethnic group and of the total population in Bulgaria by 2050 (base year - 2015).

The decline of the ethnic Bulgarian population is expected to continue and in absolute terms this decline will have the following dimensions: between 39700 people per year according to the optimistic scenario and 72500 people per year according to the pessimistic one. By the end of the projected period (2050), the number of the country's population is expected to have dropped under 5 million people according to the pessimistic and the realistic scenario respectively. In case of a significant increase of the birth rates, the number of the population of Bulgaria will only drop to 5749000 people by 2050 .

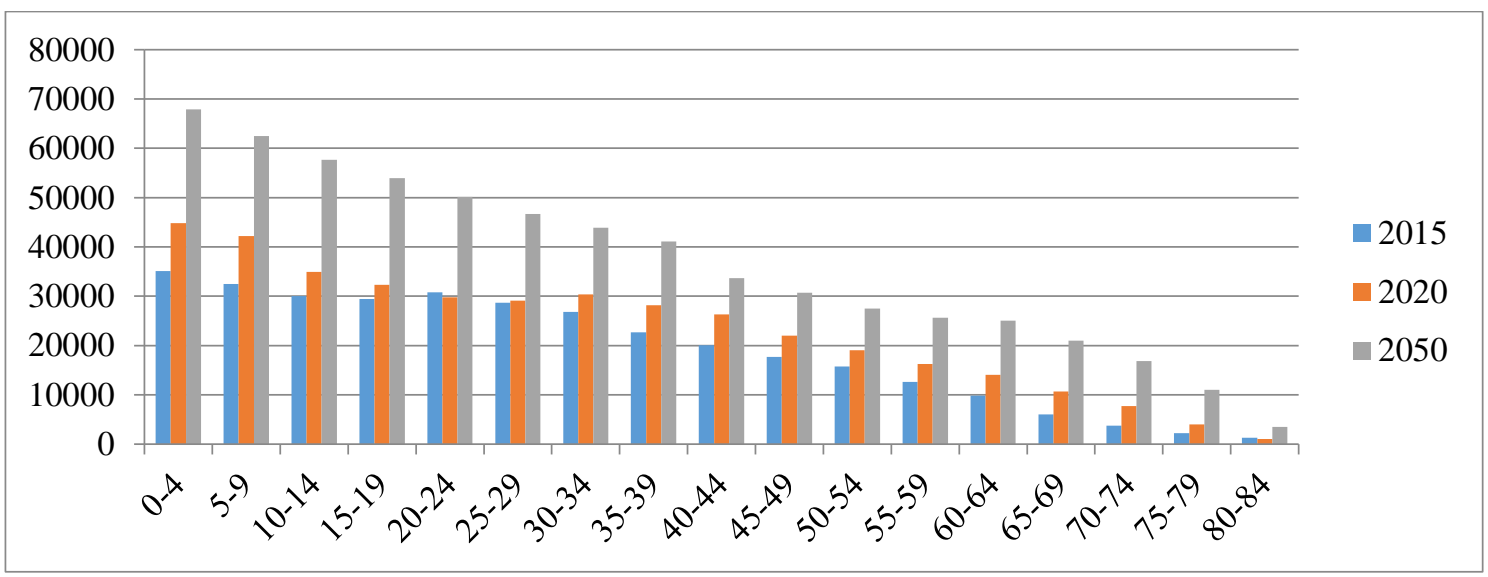

Figure 3. Projected distribution of the Roma population by age groups.

Considering the accumulation of Roma population in the younger age groups, the significant difference between the average age of the Roma population and that of the ethnic Bulgarian population (the latter being some 15 years older), comes as no surprise. For example, as of 2020 the mean age of the ethnic Bulgarian population will be around 43-45 years, while that of the Roma - 29-31. By the end of the projected period, the gap between the two ethnic groups will remain more or less the same and in the realistic scenario the ethnic Bulgarians will be aged 46-47, while the Roma will be aged 31-32 on the average by 2050 . 
At the beginning of the projected period (2015), the Roma population aged 0-14 years (under working age) accounts for $29.5 \%$ of the total Roma population and their number is 97000 according to the official census data and 199000 according to the expert assessment. Depending on the scenarios adopted, as well as the values of the fertility rate, this age group will increase by $37.0 \%$ according to the realistic scenario and by $54.3 \%$ according to the optimistic one, while the pessimistic scenario projects only a slight increase of just $1.0 \%$.

a)

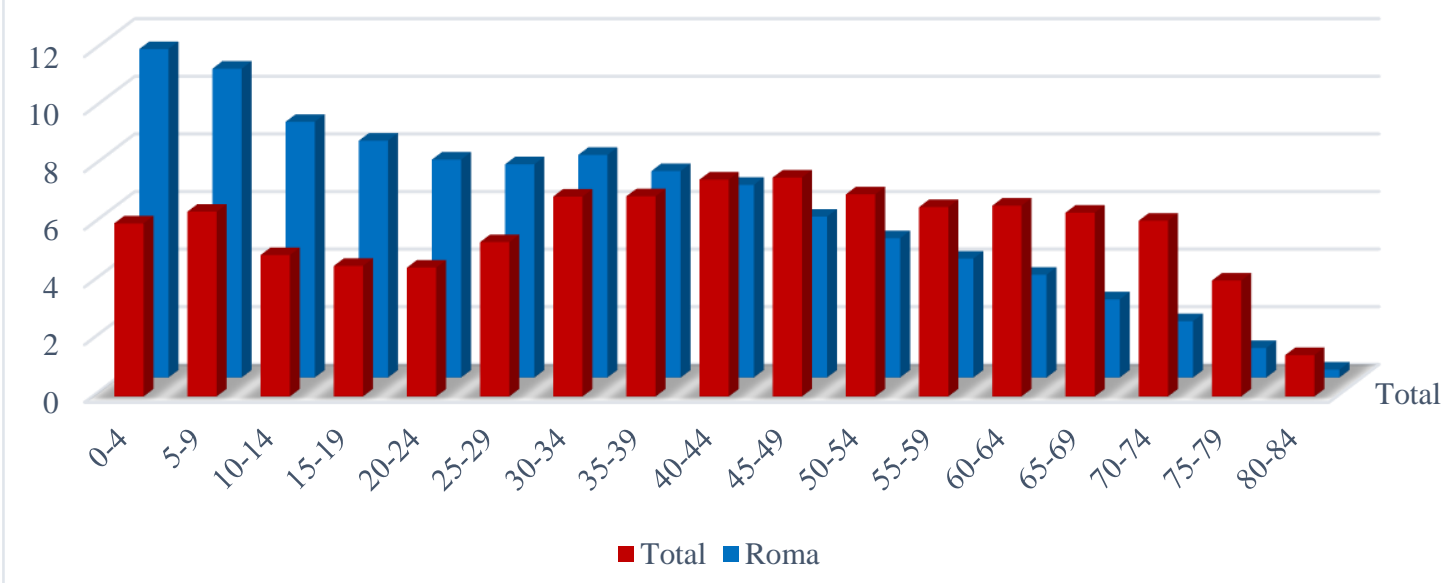

b)

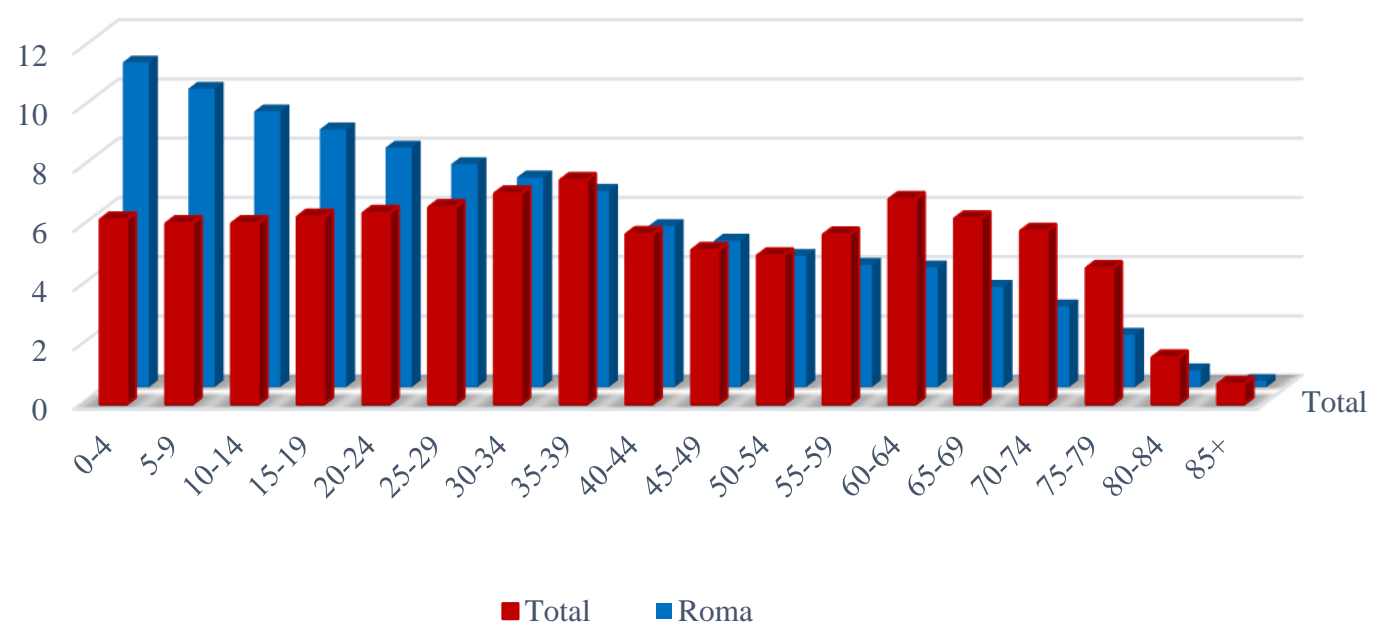

Figure 4. Expected relative share (\%) of the Roma ethnic group and of the total population in Bulgaria by 2020 (a) and 2050 (b). 
According to the output data, the working age Roma population (aged 15-64) was 220 000 according to the official census data, and 438000 according to the expert assessment, accounting for $65.0 \%$ of the total Roma population. The number of Roma people in working age will increase by $41.1 \%$ according to the realistic scenario, by $52.9 \%$ according to the optimistic scenario and by $17.4 \%$ according to the pessimistic scenario. In 2050 this age group will reach between 290000 and 378000 people according to the official data and between 593000 and 772000 according to the expert assessment.

At the beginning of the projected period, the Roma population aged 65+ was around 13 000 people according to the official data and some 27000 people according to the expert assessment, constituting just $4.1 \%$ of the total Roma population in the country.

Given that by 2050 this age group will be formed by the population born before the projected period, its number is expected to increase relatively by $128.0 \%$ and by 2050 to reach 53000 people according to the official data and 109000 according to the expert assessment. The relative share of the Roma population aged $65+$ will be somewhere between $8.7 \%$ and $12.3 \%$ of the total Roma population. The increase in the relative share of the above working age Roma population comes as a result of the increase of the average life span, as well as the entry of generations born before 1985, when the natural growth rate exceeded $25.0 \%$. The Roma population aged 65+, unlike in the cases of the Bulgarian ethnic group, forms an insignificant share and accounts for $4.9 \%$ of the total Roma population according to the official data and $10.1 \%$ according to the expert assessment.

The breaking down into age groups allows us to estimate the age dependency ratio of the Roma population, which represents the ratio between the population aged 0-14 and 65+ years on the one hand, and the working age population (aged 15-64) on the other. For example, in 2011 there were 10 people of Roma people at above working age per each 100 Roma people at working age,. This figure will not change until 2020, after which an increase of 4 percentage points will be observed by 2050 according to the optimistic scenario, by 5 percentage points according to the realistic one and by 8 percentage points according to the pessimistic scenario. The age dependency ratio of the senior population will continue to increase for the ethnic Bulgarian population. In the coming decades the aging of the Bulgarian population will accelerate. This is a consequence of the decline of the birth rates and the increase of the life expectancy at birth. The accelerated aging process is considered irrevocable and cannot be terminated, but can only be relieved. Due to the growing share of the population aged $65+$, as of 2011 there were 31 people aged $65+$ per 100 people aged 15-64, which ratio will change according to the different scenarios of the projection to 33 (optimistic) and 44 (pessimistic).

\section{PARAMETERS OF THE DEMOGRAPHIC PROJECTION BASED ON THE LEVEL OF MIGRATION}

Two periods in the Bulgarian Roma migration since 1989 can be clearly outlined: a period of weak migration mobility till the beginning of the $21^{\text {st }}$ century, and a second period (the first decade of the $21^{\text {st }}$ century) of increased emigration as a result of Bulgaria's accession to the so-called Schengen "White List" (April, 2001) and the EU accession of the country $\left(1^{\text {st }}\right.$ January, 2007) which, together with the socio-economic problems that accompany the so-called transitional period, prove to be of highest significance for the Bulgarian Roma to decide to emigrate.

According to Pamporov [6], until 2001 the Roma are the least mobile ethnic community in the country. Tomova's [10] assertion is similar - "In spite of the stereotype of the 
Roma being the most mobile part of the population, in the 1993-2001 period they appear to be the most stationary group in the country." The low migration mobility of the Roma in that period is confirmed by the conducted sociological survey representing the Roma community within the project "European Inclusion - data transfer and exchange of best practices between the countries Romania, Bulgaria, Italy and Spain concerning the inclusion the Roma population" [1], which states that only $1.5 \%$ of the respondents have worked abroad before January $1^{\text {st }}, 2002$. The increased levels of unemployment and poverty in Bulgaria make Roma respondents seek opportunities for their survival abroad, possibly through their relatives who are already there. The data from the EUINCLUSIVE survey from 2012 [1] suggest that the ongoing economic crisis fuels labor emigration rather than deterring it, since the desire to work abroad increases among the Roma. About $22.0 \%$ of the respondents have attitudes and a desire to emigrate, but only a little more than half of them $(54.0 \%)$ are certain of their future departure. This means that most likely a little less than $22.0 \%$ of them will actually depart [1]. Data from the "Health status and access of the Roma to health care" study of the Open Society Institute from 2007 show that since $200418.0 \%$ of the members of the Roma households have worked abroad for different periods of time - most commonly two people per family. Most of the stays abroad were short-term stays, which illustrates the temporary and circular character of the migration of the Roma population.

According to various studies on the range and the attitude of the population to emigrate from the country (taking into account also the short-term nature of the migration processes among the Roma), as well as the "Updated National Strategy for Demographic Development of Bulgaria (2012 - 2030)" [12] and the NSI projections, the migration outflow will stabilize at around 6000 - 8000 people per year. When calculating the rate of migration for the second scenario, the projected average number of emigrants is taken into account, which amounts to 7000 people a year, or a coefficient of migration growth of the population of $-0.9 \%$.

\section{CONCLUSION}

Based on the results of the population projection and on the existing trends concerning the demographic development of the Roma ethnic group, several key conclusions can be made:

- Estimating the real number and the spatial distribution of the Roma in Bulgaria will continue to represent an obstacle in solving the problems associated with that ethnic community, since a differentiated approach is required toward the different socioethnic communities depending mostly on their educational level and age structure, their cultural characteristics, employment and migration attitudes.

- The growing number of Roma in Bulgaria will continue to represent a social threat to a growing number of settlements and regions, especially in terms of local administrative capacity, quality of the labor force, investment attractiveness, etc.

- The cohabitation of younger Roma population with aging ethnic Bulgarian population will continue to represent a challenge for conducting socio-economic policies of all kinds, since the two groups of population have very different needs and requirements which requires regionally differentiated and in the same time - socio-demographically differentiated policies.

- Emigration of Roma people is a demographic development factor of a growing significance, the prediction of which will be crucial to making projections of the Roma population in the future. 
- The Roma people will continue to represent a problem, unless their educational level and professional qualification don't improve significantly over the next couple of decades.

\section{ACKNOWLEDGMENTS:}

The study was carried out within the framework of a contract with The National Scientific Research Fund №. DN 15/7 2017. "Spatial segregation and its impact on the social integration of the Roma people in Harman Mahala, Plovdiv".

\section{REFERENCES:}

[1] Bogdanov, G. et al. Report on public policies for Roma integration in Bulgaria and the main of the socio-economic inclusion of the Roma community, within the "EU INCLUSIVE" Project - Data transfer and exchange of best practices between Romania, Bulgaria, Italy and Spain concerning the inclusion of the Roma population, 2012, $71 \mathrm{p}$. http://osi.bg/downloads/File/2012/Final\%20Report_FNS_26_Jan_2012.pdf (in Bulgarian) (Accessed 15 Sep. 2016)

[2] Ilieva, N. The Roma in Bulgaria - number and localization from the Liberation to the beginning of the 21st century. Sofia, 2013. ISBN 978-954-9649-09-3, 236 p. (in Bulgarian)

[3] Liegeois, Jean-Pierre. Roma, Gypsies, Travellers. ISBN-10: 9287123497, Council of Europe, 1994, $323 \mathrm{p}$.

[4] Marushiakova, E., V. Popov. The Roma in Bulgaria, Sofia, 1993, Klub 90, 239 p. (in Bulgarian)

[5] Pamporov, A. Social distances and ethnic stereotypes of the minorities in Bulgaria. Open Society Institute, Sofia, 2007, 139 p. (in Bulgarian)

[6] Pamporov, A. et al. The Roma in Bulgaria. Sofia, 2008, Open Society Institute, ISBN 978954-9828-61-0, 93 p. (in Bulgarian)

[7] Popov, V. Bulgarians and gypsies (ethnic relations). - In: Ethnic picture of Bulgaria, 1993 (in Bulgarian)

[8] Tomova, I. The gypsies in the transitional period, (International Center for Minority Studies and International Relations, Sofia, 1995, 127 p. (in Bulgarian)

[9] Tomova, I. Health and the Roma community - analysis of the situation in Europe (Preliminary national report). Madrid, 2009, ISBN: 978-84-692-5537-7, 146 p. (in Bulgarian) http://www.gitanos.org/upload/87/58/BULGARIA-final-baja.pdf (Accessed 21 Sep. 2016)

[10] Tomova, I. Ethnicity and the emigration of the population in the postcommunist period in Bulgaria. - In: Migration, gender and intercultural relations in Bulgaria. IMIR, Sofia. 2011, ISBN: 978-954-8872-67-6, pp. 257-290. (in Bulgarian)

[11] Tomova, I., A. Pamporov, V. Milenkova. The socio-economic situation of the vulnerable ethnic minorities in Bulgaria. Institute of Sociology - Bulgarian Academy of Sciences, Sofia, 2009

[12] Updated National Strategy for Demographic Development of the Population of Bulgaria 2012-2030 (in Bulgarian) https://www.president.bg/docs/1352302457.pdf (Accessed 20 Aug. 2016) 